\title{
Substâncias antifúngicas constitutivas e induzidas em folhas e suspensões celulares de Rudgea jasminoides (Cham.) Müll. Arg. (Rubiaceae)
}

\author{
MARISA DE CACIA OLIVEIRA ${ }^{1}$ KELLY SIMÕES² e MÁRCIA REGINA BRAGA²,3
}

(recebido: 12 de junho de 2008; aceito: 04 de maio de 2009)

\begin{abstract}
Constitutive and induced antifungal compounds in leaves and cell suspension cultures of Rudgea jasminoides (Cham.) Müll. Arg. (Rubiaceae)). Rudgea jasminoides (Cham.) Müll. Arg. is a woody Rubiaceae species from tropical forest that synthesized antifungal secondary metabolites when challenged by fungi. Members of the Rubiaceae are among the few plants that are easily taken into cell cultures to produce substantial amounts of secondary products that surpass those of the whole plant. In this work we analyzed the presence of constitutive and induced antifungal compounds produced by leaves and cell suspension cultures of this species. Oligogalacturonides (OGAs), salicylic acid (AS), nitric oxide (NO), and yeast $\beta$-glucan fragments were used as elicitors. Constitutive compounds with antifungal activity were detected in cell suspension cultures of $R$. jasminoides, mainly during the stationary growth phase. They were found in higher diversity and amounts than those present in leaves. Treatment with $\beta$-glucan fragments increased the production of constitutive compounds and induced the synthesis of antifungal metabolites absent in non-elicited cultures (phytoalexins), mainly during the exponential growth phase. OGAs derived from $R$. jasminoides leaf cell walls showed similar effect. Under our experimental conditions, the endogenous signaling molecules salicylic acid and nitric oxide were toxic to the cells and did not act as elicitors of antifungal compounds in suspension cultures of $R$. jasminoides. Our data indicate that cell suspension cultures of $R$. jasminoides are able to synthesize antifungal compounds and their production can be enhanced by fungal or plant elicitors.
\end{abstract}

Key words - antifungal compounds, cell suspension, elicitors, phytoalexin, Rubiaceae

RESUMO - (Substâncias antifúngicas constitutivas e induzidas em folhas e suspensões celulares de Rudgea jasminoides (Cham.) Müll. Arg. (Rubiaceae)). Rudgea jasminoides (Cham.) Müll. Arg. é uma rubiácea arbórea nativa da floresta tropical que sintetiza metabólitos secundários antifúngicos, quando em contato com fungos. Membros da família Rubiaceae estão entre as poucas plantas facilmente mantidas em cultura de tecidos e que produzem quantidades substanciais de metabólitos secundários que ultrapassam os níveis normalmente encontrados na planta intacta. Neste trabalho foi analisada a presença de compostos antifúngicos constitutivos e induzidos produzidos por folhas e suspensões celulares dessa espécie. Oligogalacturonídeos (OGAs), ácido salicílico(AS), óxido nítrico(NO) e fragmentos de $\beta$-glucano de leveduras foram usados como eliciadores. Substâncias constitutivas com atividade antifúngica foram detectadas nas suspensões celulares de $R$. jasminoides, principalmente na fase estacionária do crescimento das culturas. Essas substâncias foram encontradas em maior diversidade e quantidade quando comparadas às das folhas. $O$ tratamento com fragmentos de $\beta$-glucano de leveduras aumentou a produção de substâncias antifúngicas constitutivas e induziu a síntese de compostos antifúngicos ausentes nas culturas não eliciadas (fitoalexinas), principalmente na fase de crescimento exponencial. OGAs derivados da parede celular de folhas dessa espécie também promoveram efeito similar. Nas condições experimentais utilizadas, os sinalizadores endógenos ácido salicílico e óxido nítrico foram tóxicos e ineficazes na ativação da síntese de metabólitos de defesa nas culturas celulares de $R$. jasminoides. Os resultados obtidos neste trabalho indicam que suspensões celulares de $R$. jasminoides sintetizam substâncias com atividade antifúngica, cuja produção pode ser aumentada pelo uso de eliciadores de fungos e plantas.

Palavras-chave - eliciadores, fitoalexinas, Rubiaceae, substâncias antifúngicas, suspensões celulares

\section{Introdução}

Os metabólitos secundários vegetais exercem uma grande variedade de funções fisiológicas e ecológicas, que incluem respostas de defesa contra agentes bióticos e abióticos, sinalização química para polinizadores e

1. Universidade Tecnológica Federal do Paraná, Coordenação de Agronomia, Campus de Pato Branco, PR, Brasil.

2. Instituto de Botânica, Seção de Fisiologia e Bioquímica de Plantas, Caixa Postal 3005, 01061-970 São Paulo, SP, Brasil.

3. Autor para correspondência: bragamr@ig.com.br dispersores e simbiose entre plantas e microorganismos, entre outras. Essas substâncias pertencem a diferentes classes químicas, tendo distribuição heterogênea em diferentes grupos taxonômicos, órgãos e tecidos vegetais (Gottlieb 1982). Muitos metabólitos secundários são normalmente sintetizados e acumulados constitutivamente nas plantas, enquanto outros têm sua biossíntese induzida apenas após a ativação por fatores do ambiente (McCall \& Karban 2006).

Culturas de células e tecidos vegetais têm sido utilizadas como alternativas ao uso da planta intacta para o estudo e a produção de diversos metabólitos 
secundários (Chong et al. 2005, Seydel \& Dörnenburg 2006, Vitali et al. 2006, Warzecha et al. 2007). Moléculas liberadas de microorganismos ou da própria planta, ou ainda, substâncias de natureza abiótica, todas denominadas genericamente de eliciadores, vêm sendo utilizadas para induzir rotas de biossíntese de metabólitos secundários em suspensões celulares, visando elucidar sua síntese, distribuição e acúmulo (Barz et al. 1990, Chong et al. 2005, Zhao et al. 2005, Vasconsuelo \& Boland 2007, Orbán et al. 2008). As moléculas de origem vegetal incluem oligogalacturonídeos (fragmentos de polissacarídeos de parede celular) e sinalizadores intracelulares e sistêmicos, como ácido salicílico, jasmonatos e óxido nítrico, entre outros (Zhao et al. 2005, Vasconsuelo \& Boland 2007, Wang et al. 2007, Hu \& Zhong 2008, Orbán et al. 2008). Eliciadores derivados de $\beta$-glucanos de paredes de fungos, tais como Saccharomyces cerevisiae, são altamente ativos na indução da síntese de metabólitos antimicrobianos (fitoalexinas) em diversas espécies vegetais (Hahn 1996).

A família Rubiaceae caracteriza-se quimicamente pela presença de compostos do grupo das quinonas, principalmente antraquinonas, naftoquinonas e hidroquinonas (Han et al. 2001, 2002, Akhtar et al. 2006, Sang \& Ho 2006, Orbán et al. 2008), porém, outros como iridóides (Bolzani et al. 1997, Dinda et al. 2006), triterpenos e saponinas (Young et al. 1998) são freqüentes. Em muitas espécies de Rubiaceae, metabólitos secundários têm sido isolados a partir do cultivo de células em suspensão (Han et al. 2001, Collu et al. 2002, Yamazaki et al. 2003, Orbán et al. 2008).

Em Rudgea jasminoides (Cham.) Mull. Arg., uma rubiácea arbórea nativa da floresta tropical, o estudo da produção de metabólitos de defesa revelou que esta espécie produz substâncias antifúngicas em resposta à exposição a microorganismos (fitoalexinas), mas sua síntese varia sazonalmente (Braga et al. 1986, 1991). Stella \& Braga (2002), em função dessa variação, estabeleceram suspensões celulares de $R$. jasminoides, a partir de calos derivados de explantes foliares. Recentemente, Oliveira et al. (2007) descreveram a ocorrência de antraquinonas como metabólitos secundários constitutivos e de uma naftoidroquinona induzida em suspensões celulares dessa espécie.

No presente trabalho a ocorrência de compostos antifúngicos constitutivos e induzidos por eliciadores bióticos é descrita em suspensões celulares de $R$. jasminoides e comparada com aquelas encontradas em folhas de indivíduos da espécie crescendo em condições naturais.

\section{Materiais e métodos}

Material vegetal - Folhas frescas de Rudgea jasminoides, sem lesões visíveis, foram coletadas na mata da Reserva Biológica das Fontes do Ipiranga, São Paulo - SP, lavadas em água corrente e desinfetadas com uma solução de hipoclorito de sódio comercial a $15 \%$ ( $0,3 \%$ de cloro ativo), por 10 minutos. Discos de aproximadamente dois centímetros de diâmetro foram cortados das folhas com o auxílio de um furador de rolhas e submetidos à extração de substâncias antifúngicas constitutivas ou utilizados para o ensaio de indução de fitoalexinas, descritos abaixo.

Calos friáveis, obtidos conforme descrito por Stella \& Braga (2002), foram transferidos para frascos Erlenmeyers de $125 \mathrm{~mL}$ contendo meio de cultura MS (30 mL) (Murashige \& Skoog 1962), complementado com água de coco $\left(50 \mathrm{~mL} \mathrm{~L}^{-1}\right)$ e $1 \mathrm{mg} \mathrm{L}^{-1}$ de picloram (ácido 4-amino-3,5,6-tricloro-2piridinacarboxílico), mantidos a $26^{\circ} \mathrm{C}$, sob agitação constante (100 rpm) e fotoperíodo de 12 horas de luz $\left(50 \mu \mathrm{mol} \mathrm{m}^{-2} \mathrm{~s}^{-1}\right)$, por tempos variáveis. Cerca de dois gramas de células na fase exponencial de crescimento (nove a dez dias de idade) foram transferidos para frascos Erlenmeyers de $125 \mathrm{~mL}$ contendo meio de cultura MS $(30 \mathrm{~mL})$ e utilizados nos ensaios de indução.

Eliciadores - Fragmentos de $\beta$-glucanos da levedura Saccharomyces cerevisiae Meyen ex E. C. Hansen foram obtidos através de autoclavagem de fermento biológico comercial granulado seco (Fermix) $\left(100 \mathrm{mg} \mathrm{mL}^{-1} \mathrm{em}\right.$ água destilada), a $121^{\circ} \mathrm{C}$, em $1,5 \mathrm{~atm}$, por 15 minutos. Após o resfriamento, o extrato foi centrifugado, sendo o sobrenadante recolhido e quantificado quanto ao teor de açúcares totais (Dubois et al. 1956). Foi utilizado um miligrama em equivalentes de glucose $\mathrm{mL}^{-1}$ nos ensaios de eliciação.

Os oligogalacturonídeos (OGAs) foram extraídos de paredes celulares de folhas e de suspensões celulares de $R$. jasminoides, conforme descrito por Braga et al. (1998) e Fry (1988), respectivamente. Cerca de $10 \mathrm{mg}$ de cada material foram suspensos em um mililitro de água destilada e autoclavados por 50 minutos, a $121^{\circ} \mathrm{C}$ e 1,5 atm (Braga et al. 1998). Os sobrenadantes recolhidos por centrifugação (10 min, $2000 \times g$ ) foram submetidos à determinação de açúcares totais (Dubois et al. 1956) e ácidos urônicos (Filisetti-Cozzi \& Carpita 1991), sendo utilizados como soluções eliciadoras (200 $\mu \mathrm{g}$ de equivalentes de ácidos urônicos $\mathrm{mL}^{-1}$ ).

Nitroprussiato de sódio (SNP), um doador de óxido nítrico (NO), foi solubilizado em água destilada e a solução filtrada em Millipore 0,22 $\mu \mathrm{m}$, na ausência de luz. Para a eliciação foram utilizadas concentrações de 0,1 a $7 \mu \mathrm{M}$. Ácido salicílico (AS) Synth foi preparado em etanol a $20 \%$ e aplicado em concentrações de 50 a $400 \mu \mathrm{M}$.

Ensaios de indução - Para os ensaios de eliciação, os discos foliares com pequenas lesões na face abaxial, feitas com bisturi, foram incubados com $50 \mu \mathrm{L}$ de extrato de leveduras ( $\beta$-glucano), na concentração de $0,5 \mathrm{mg}$ em equivalentes de glucose $\mathrm{mL}^{-1}$ ou água destilada autoclavada (controle) e 
mantidos por 48 horas, a $26{ }^{\circ} \mathrm{C}$ em placas de Petri, com papel filtro umedecido.

Suspensões celulares com nove (fase exponencial de crescimento), 20 (fase estacionária inicial) ou 27 dias (fase estacionária tardia) foram inoculadas, em ensaios distintos, com eliciador de extrato de leveduras, OGAs, SNP e AS. Os controles receberam volumes idênticos de água destilada estéril. As culturas tratadas foram incubadas a $26^{\circ} \mathrm{C}$, sob agitação contínua (100 rpm), por 96 horas (tempo estabelecido como o melhor para a indução, em ensaios preliminares), exceto para SNP (doador de óxido nítrico) cuja incubação foi de 240 horas.

Extração de substâncias antifúngicas - Os discos foliares tratados e controles foram submetidos a extrações orgânicas com etanol e acetato de etila. Cerca de oito discos foliares $(0,61 \mathrm{~g})$ foram colocados em frascos tipo Erlenmeyer para extração com etanol a $40 \%$ (20 mL g $\mathrm{m}^{-1}$ de matéria fresca), sob agitação, por um período de quatro horas, por duas vezes.

As células de $R$. jasminoides cultivadas em suspensão resultantes dos ensaios de indução foram recolhidas por filtração em náilon pele de ovo. As células $(0,6$ a 2,0 g de matéria fresca) foram extraídas com etanol conforme descrito para os discos foliares.

Os extratos etanólicos de discos de folhas e células foram concentrados em evaporador rotatório até $50 \%$ de seu volume inicial, submetidos à partição com igual volume de acetato de etila por duas vezes e a fração orgânica resultante foi filtrada em sulfato de sódio anidro para completa eliminação da água. Os extratos foram secos em evaporador rotatório e retomados em 1/100 de seu volume inicial em acetato de etila.

Após a separação das células, os meios de cultura também foram extraídos com igual volume de acetato de etila, conforme descrito acima.

Detecção de compostos antifúngicos - Alíquotas dos extratos $\mathrm{em}$ acetato de etila foram submetidos à cromatografia em camada delgada em placas de sílica-gel 60 Merck, tendo como sistema de solventes clorofórmio:metanol $(99: 1 \mathrm{v} / \mathrm{v})$. A detecção da presença de substâncias antifúngicas foi efetuada através de ensaio de bioautografia, utilizando suspensão do fungo Cladosporium sphaerospermum Pemzig como revelador (Homans \& Fuchs 1970).

Determinação de parâmetros de crescimento e da viabilidade celular - As suspensões celulares utilizadas nos ensaios de indução foram avaliadas quanto ao conteúdo de matéria fresca, matéria seca, $\mathrm{pH}$ e volume do meio de cultivo. A matéria seca foi obtida por secagem de alíquotas das células a $60{ }^{\circ} \mathrm{C}$ em estufa até peso constante.

Para determinação da viabilidade celular, uma alíquota correspondente a $100 \mathrm{mg}$ das suspensões celulares utilizadas nos ensaios de indução foi avaliada por método de penetração seletiva do corante Azul de Evans (Turner \& Novacky 1974). As células foram colocadas em tubos cônicos contendo dois mililitros de meio de cultura, sendo posteriormente centrifugadas $(1450 \times \mathrm{g}, 5 \mathrm{~min})$, o sobrenadante descartado e as células ressuspensas em um mililitro da solução do corante $(0,025 \%$ p/v). Após incubação por $15 \mathrm{~min}$ a temperatura ambiente, uma nova centrifugação foi efetuada, sendo o sobrenadante descartado e as células lavadas com meio de cultura e novamente centrifugadas. As células foram tratadas com cinco mililitros de metanol a $50 \%$ contendo $1 \%$ de dodecil sulfato de sódio (SDS) e incubadas por $30 \mathrm{~min}$ a $50{ }^{\circ} \mathrm{C}$. Após centrifugação, o sobrenadante foi analisado em espectrofotômetro Shimadzu a $600 \mathrm{~nm}$. A mortalidade de $100 \%$ foi obtida por células submetidas à fervura em meio de cultura por cinco minutos.

Análise Estatística - Todos os ensaios foram realizados em triplicatas. Os resultados foram submetidos à ANOVA, utilizando o Teste de Tukey $(P<0,05)$ para comparação de médias.

\section{Resultados e discussão}

Abioautografia do extrato de folhas de $R$. jasminoides revelou a presença de vários compostos constitutivos com atividade antifúngica (figura 1A), indicando que indivíduos dessa espécie crescendo em seu meio natural acumulam substâncias de defesa. Braga et al. (1991) relataram que $R$. jasminoides responde à eliciação fúngica com a síntese de metabólitos antimicrobianos (fitoalexinas) e Cordeiro Neto \& Dietrich (1992) e Marques et al. (2006) demonstraram que fungos encontrados no filoplano dessa e de outras rubiáceas de mata são capazes de desencadear a resposta fitoalexínica em plantas nativas e cultivadas. Desse modo, as substâncias antifúngicas detectadas nas folhas de $R$. jasminoides podem ser sintetizadas constitutivamente pela planta ou ser conseqüência da indução por microrganismos presentes na superfície foliar.

A produção desses metabólitos também foi detectada em suspensões celulares dessa espécie, sendo observado aumento no número de zonas antifúngicas e na intensidade das mesmas com o crescimento da cultura (figuras 1B-D). Nenhuma substância antifúngica foi detectada nos meios de cultura das suspensões celulares de $R$. jasminoides, evidenciando que as substâncias presentes nas células não são difundidas ou exsudadas para o meio (dados não mostrados). O grande acúmulo de metabólitos antifúngicos constitutivos observado nas fases tardias de crescimento era esperado, já que nos estágios iniciais do cultivo in vitro, toda energia está voltada para a divisão e o crescimento celular, de modo que o metabolismo essencial para tais processos predomina em relação ao metabolismo secundário (Banthorpe 1994). Em relação aos parâmetros de crescimento avaliados, a cultura de 


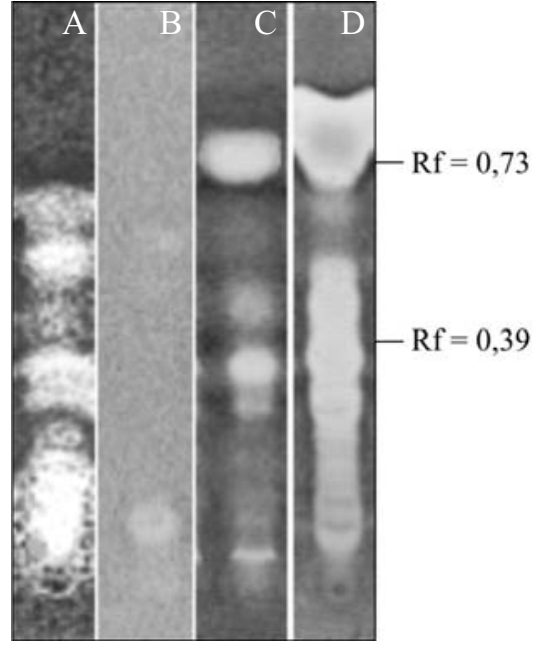

Figura 1. Bioautografia de extratos de folhas (A) e de células de Rudgea jasminoides cultivadas em suspensão, com 9 (B), 20 (C) e 27 (D) dias de idade sem tratamento com eliciadores. As cromatoplacas foram desenvolvidas em clorofórmio: metanol $(99: 1 \mathrm{v} / \mathrm{v})$ e reveladas com suspensão de esporos do fungo Cladosporium sphaerospermum. Foram utilizados $50 \mu \mathrm{L}$ dos extratos foliar/celulares.

Figure 1. Bioautography of leaf(A) and cell suspension extracts of $R$. jasminoides with 9 (B), 20 (C) e 27 (D) days of culture, without treatment with elicitors. The plates were developed in chloroform: methanol $(99: 1 \mathrm{v} / \mathrm{v})$ and revealed with spore suspension of Cladosporium sphaerospermum. Fifty $\mu \mathrm{L}$ of foliar/cellular extracts were applied on the plates.

$R$. jasminoides seguiu o padrão típico, com ganhos de matérias fresca e seca com o aumento da idade (dados não mostrados), conforme já relatado por Stella \& Braga (2002).

Comparando os resultados obtidos com os extratos de folhas e de células, nota-se que foram encontradas zonas de inibição do crescimento do fungo revelador com mesma razão de migração na cromatoplaca, em ambos os materiais ( $\mathrm{Rf}=0,39)$, o que sugere que as suspensões celulares sintetizam compostos constitutivos similares àqueles encontrados na planta. Entretanto, nas suspensões celulares na fase estacionária de crescimento ( 20 e 27 dias) foram detectados outros compostos, aparentemente ausentes nos extratos foliares $(\mathrm{Rf}=0,73)$.

Rubiaceae representa um dos poucos grupos vegetais no qual a produção de metabólitos secundários in vitro ultrapassa aquela observada nas plantas intactas (Abdullahet al. 1998). Para R.jasminoides, aparentemente as suspensões também produzem maior quantidade e diversidade de metabólitos antifúngicos quando comparadas às folhas (figura 1). Conforme descrito para 17 outras espécies de Rubiaceae pertencentes aos gêneros Asperula, Rubia, Sherardia (Schulte et al. 1984) e Morinda (Abdullah et al. 1998, Komaraiah et al. 2005), também em $R$. jasminoides, a otimização das condições de cultivo poderia ser uma alternativa para incrementar a produção de metabólitos secundários constitutivos.

Eliciadores ou moléculas sinalizadoras endógenas, cuja ação pode ativar a síntese dos metabólitos secundários vegetais, têm sido utilizados para aumentar o acúmulo de substâncias de interesse produzidas por suspensões celulares, conforme recentemente demonstrado em Rubia tinctorium L. (Orbán et al. 2008). Células de $R$. jasminoides também respondem com o acúmulo e síntese de metabólitos de defesa quando induzidas por diferentes eliciadores, principalmente durante a fase de crescimento exponencial das culturas (figuras 2,3).

Ensaios realizados com extrato de leveduras (que contém fragmentos de $\beta$-glucano como os eliciadores mais ativos) mostraram que houve indução da produção de substâncias antifúngicas nas suspensões celulares de $R$. jasminoides (figura 2). Células dessa espécie responderam à presença do eliciador desde os nove até os 20 dias de cultivo (figuras 2A, B). Entretanto, nas células que já atingiram a fase estacionária de crescimento (27 dias) as moléculas indutoras não promoveram aumento e/ou síntese de compostos com atividade antifúngica, com $\mathrm{Rfs}$ distintos daqueles acumulados constitutivamente (figura 2C). Do mesmo modo, esse eliciador também não foi eficaz em promover a indução da produção de substâncias de defesa nos discos das folhas obtidas das plantas crescendo em ambiente natural (figura 2D).

O extrato de leveduras também induziu a produção de outras substâncias antifúngicas, ausentes nas células (por exemplo, $\mathrm{Rf}=0,59$ ), o que sugere a síntese de fitoalexinas por ação desse eliciador (figuras 2A, B). Desse modo, sua ação parece relacionada à antecipação no acúmulo de substâncias antifúngicas constitutivas e à indução da síntese de outras normalmente não acumuladas pelas células. Considerando-se que aos 9 dias (figura 1B) o acúmulo de metabólitos antifúngicos constitutivos ainda é pequeno, essa foi a idade escolhida para os demais ensaios de indução. Com pouca interferência de compostos antifúngicos constitutivos, os efeitos dos eliciadores puderam ser melhor visualizados nessa fase.

Os oligogalacturonídeos extraídos de paredes de células cultivadas em suspensão e de folhas de $R$. jasminoides nativas apresentaram efeitos distintos ao serem aplicados às suspensões celulares (figura 3). Enquanto OGAs procedentes das células não tiveram 

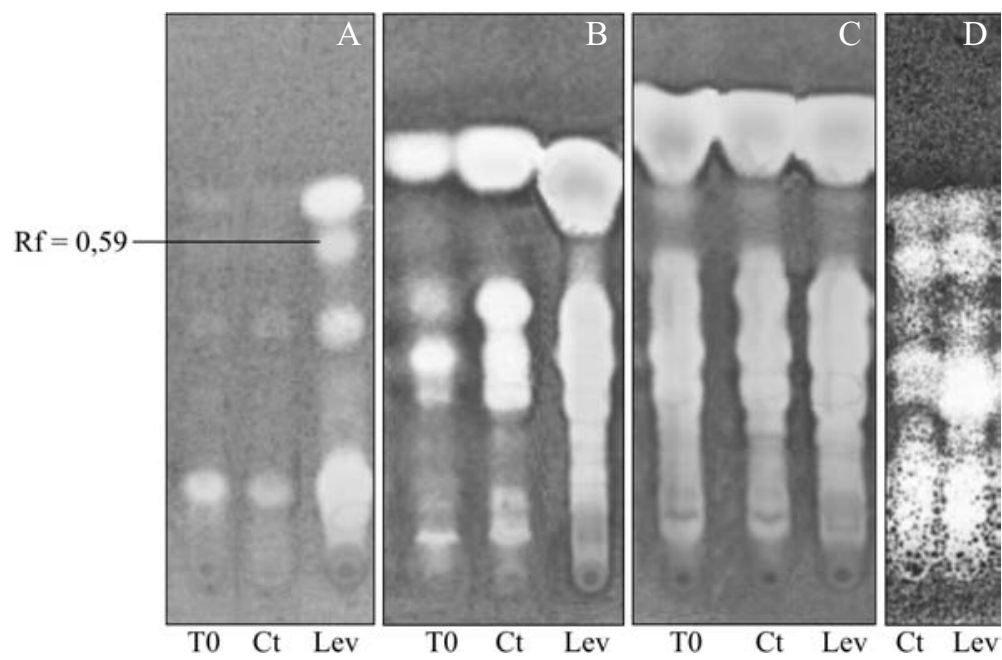

Figura 2. Bioautografia de extratos de células cultivadas em suspensão por 9 (A), 20 (B) e 27 dias (C) e de folhas (D) de $R$. jasminoides incubadas por 96 horas com água destilada autoclavada $(\mathrm{Ct})$ ou extrato de leveduras $(\mathrm{Lev})$. ( $\mathrm{T} 0=$ extratos de células antes da eliciação). As cromatoplacas foram desenvolvidas em clorofórmio: metanol (99:1 v/v) e reveladas com suspensão de esporos do fungo Cladosporium sphaerospermum. Foram utilizados $50 \mu \mathrm{L}$ dos extratos celulares.

Figure 2. Bioautography of cell suspension extracts with 9 (A), 20 (B) and 27 (C) days of culture and leaves (D) of $R$. jasminoides, treated during 96 hours with autoclaved distilled water $(\mathrm{Ct})$ or yeast extract $(\mathrm{Lev})$. $(\mathrm{T} 0=$ cell extracts before elicitation). The plates were developed in chloroform: methanol (99:1 v/v) and revealed with spore suspension of Cladosporium sphaerospermum. Fifty $\mu \mathrm{L}$ of cellular extracts were applied on the plates.

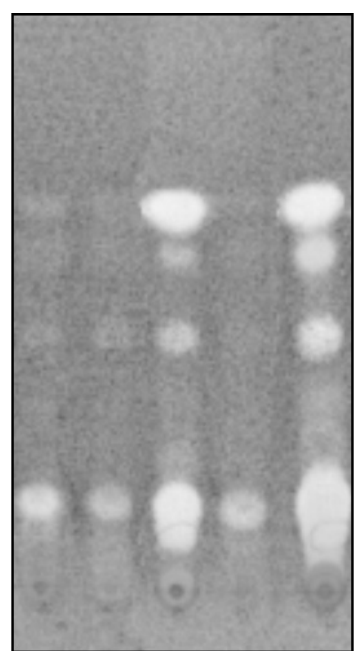

T0 Ct OGAf OGAc Lev

Figura 3. Bioautografia de extratos de células de $R$. jasminoides cultivadas em suspensão por 9 dias, incubadas por 96 horas com água destilada autoclavada $(\mathrm{Ct}), 200 \mu \mathrm{g} \mathrm{mL}^{-1}$ de OGAs obtidos de folhas (OGAf) ou de células em suspensão (OGAc) ou $1 \mathrm{mg}$ de equivalente de glucose $\mathrm{mL}^{-1}$ de extrato de leveduras (Lev). $(\mathrm{T} 0=$ extratos de células antes da eliciação, OGA = oligogalacturonídeos). As cromatoplacas foram desenvolvidas em clorofórmio: metanol (99:1 v/v) e reveladas com suspensão de esporos do fungo Cladosporium sphaerospermum. Foram utilizados $50 \mu \mathrm{L}$ dos extratos celulares. qualquer ação como indutores de compostos antifúngicos, os OGAs obtidos de folhas agiram de modo semelhante ao extrato de leveduras, aumentando a produção de substâncias constitutivas ativas (figura 3). Além disso, OGAs obtidos de células ocasionaram alcalinização do meio de cultura (figura 4A) e redução na matéria fresca (figura 4B), não sendo observado, porém, aumento da mortalidade celular (figura 4C).

Os oligogalacturonídeos (OGAs) são reconhecidos como eliciadores de respostas de defesa em vegetais (Ridley et al. 2001) e também envolvidos em diversos processos de desenvolvimento e crescimento celular (Bellincampi et al. 1996, Ridley et al. 2001). A diferença no efeito indutor de OGAs derivados de folhas e de

Figure 3. Bioautography of cell suspension extracts of $R$. jasminoides with 9 days of culture, treated during 96 hours with autoclaved distilled water $(\mathrm{Ct}), 200 \mu \mathrm{g} \mathrm{mL}^{-1}$ of OGAs from leaf (OGAf) or from cell cultures (OGAc) or $1 \mathrm{mg}$ equivalents glucose $\mathrm{mL}^{-1}$ of yeast extract $(\mathrm{Lev}) .(\mathrm{T} 0=$ cell extracts before elicitation, $\mathrm{OGA}=$ oligogalacturonides). The plates were developed in chloroform: methanol $(99: 1 \mathrm{v} / \mathrm{v})$ and revealed with spore suspension of Cladosporium sphaerospermum. Fifty $\mu \mathrm{L}$ of cellular extracts were applied in the plates. 
suspensões celulares de $R$. jasminoides poderia estar relacionada à presença de fragmentos de tamanhos diversos de OGAs, principalmente com grau de polimerização muito pequeno e que seriam responsáveis
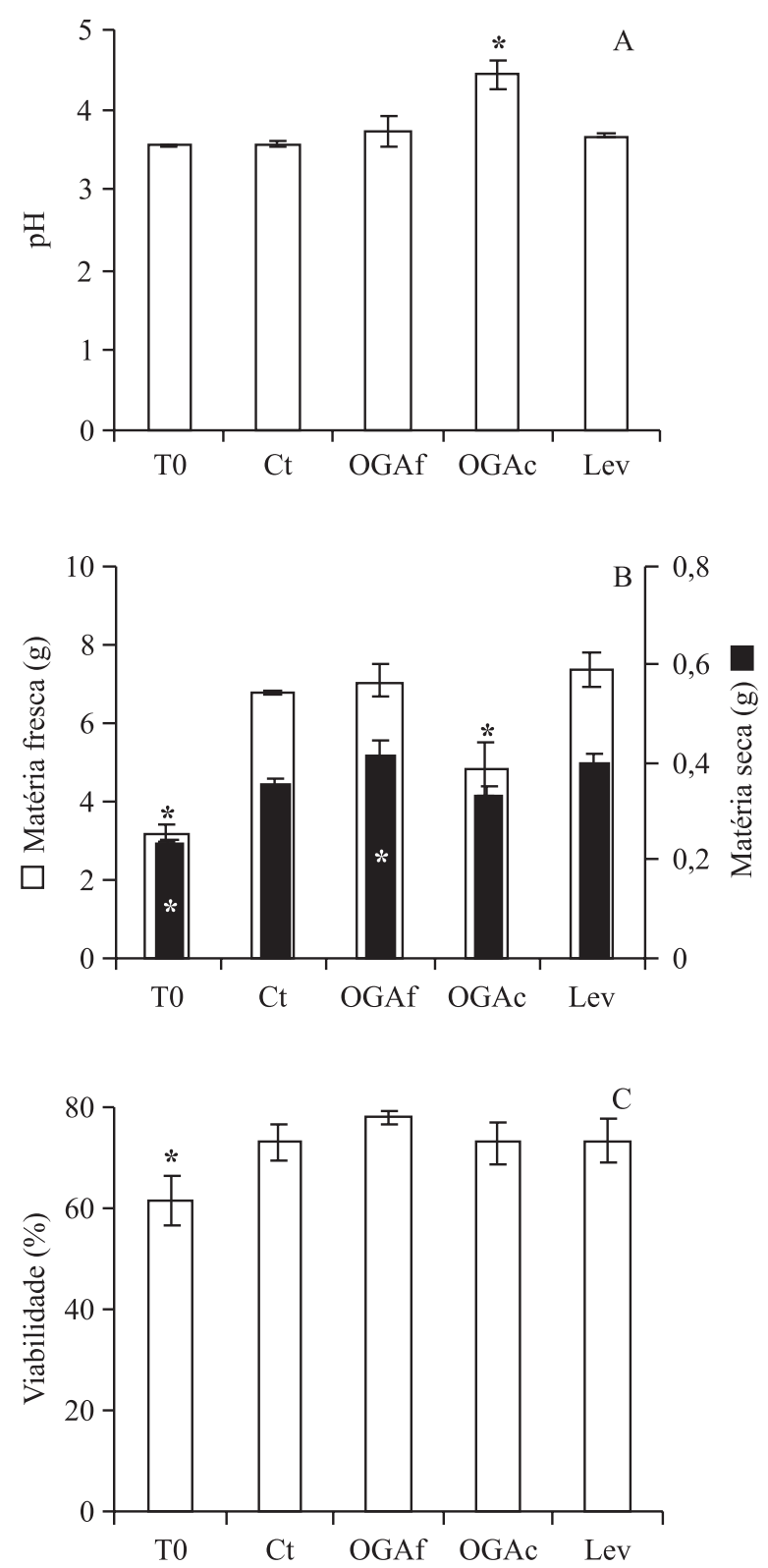

Figura 4. Valores de $\mathrm{pH}$ dos meios de cultivo (A), matérias fresca e seca (B) e viabilidade (C) de células de $R$. jasminoides cultivadas em suspensão, com 9 dias de idade, incubadas por 96 horas com água destilada autoclavada $(\mathrm{Ct}), 200 \mu \mathrm{g} \mathrm{mL}{ }^{-1} \mathrm{de}$ OGAs obtidos de folhas (OGAf) ou de células em suspensão (OGAc) ou $1 \mathrm{mg}$ de equivalente de glucose $\mathrm{mL}^{-1}$ de extrato de leveduras (Lev). ( $\mathrm{T} 0=$ extratos de células antes da eliciação, OGA = oligogalacturonídeos). As barras representam o desvio padrão das médias (triplicatas). Os asteriscos (*) indicam diferenças significativas em relação ao controle $(\mathrm{Ct})$ pelo teste de Tukey $(P<0,05)$. pelo bloqueio de síntese de compostos antifúngicos ao se ligarem a sítios específicos, responsáveis por dispararem respostas de defesa. Além de provocar um aumento significativo do pH (figura 4A) em relação aos demais tratamentos, os OGAs provenientes de paredes de células cultivadas em suspensão interferiram ligeiramente no acúmulo de massa celular (figura 4B). Mauro et al. (2002) verificaram que concentrações micromolares de OGAs foram capazes de inibir a ativação de genes induzidos por auxinas, envolvidos no crescimento e desenvolvimento em Nicotiana tabacum e sugerem que concentrações maiores seriam requeridas para induzir respostas de defesa.

As moléculas sinalizadoras óxido nítrico e ácido salicílico foram aplicadas às culturas celulares de $R$. jasminoides, apresentando resultados negativos em relação à indução (figura 5). Devido à lenta liberação de moléculas de NO pelo nitroprussiato de sódio (SNP), o tempo de incubação das culturas com o sinalizador foi estabelecido através de ensaios preliminares (dados não mostrados) em 264 horas (10 dias), o que poderia explicar a não detecção de aumento de compostos antifúngicos, uma vez que as culturas controle, nesse caso, com 19 dias já mostraram grande acúmulo de substâncias inibidoras (figura 5A). Concentrações de SNP variando de 0 a $7 \mu \mathrm{M}$ foram testadas e acima de $3 \mu \mathrm{M}$ o efeito sobre as células foi de toxicidade, reduzindo a viabilidade celular a valores inferiores a $20 \%$ (figura 6C) e, conseqüentemente, a produção de matérias fresca e seca (figura 6B). Este efeito foi notado na produção de compostos antifúngicos, com redução no acúmulo dos mesmos (figura 5A).

A inibição de crescimento correlacionada à morte celular por doadores de NO também foi observada em suspensões celulares de Citrus sinensis (L.) Osbeck após dez dias de incubação com SNP em concentrações que variaram de 0,01 a $100 \mu \mathrm{M}$ (Saviani et al. 2002). Segundo esses autores, a ausência de um mecanismo regulatório de controle da morte celular explicaria, parcialmente, a sensibilidade das células, como verificado também em $R$. jasminoides.

Figure 4. Culture medium $\mathrm{pH}$ (A), fresh and dry masses (B), and viability of 9-day-old cell suspension of $R$. jasminoides, treated during 96 hours with autoclaved distilled water (Ct), $200 \mu \mathrm{g} \mathrm{mL}^{-1}$ of OGAs from leaf (OGAf) or from cell cultures (OGAc) or $1 \mathrm{mg}$ equivalents glucose $\mathrm{mL}^{-1}$ of yeast extract $(\mathrm{Lev}) .(\mathrm{T} 0=$ cell extracts before elicitation, $\mathrm{OGA}=$ oligogalacturonides). Bars represent standard deviation of the mean of triplicates. The asterisks $(*)$ indicate significant differences in relation to control $(\mathrm{Ct})$ by Tukey $(P<0.05)$. 


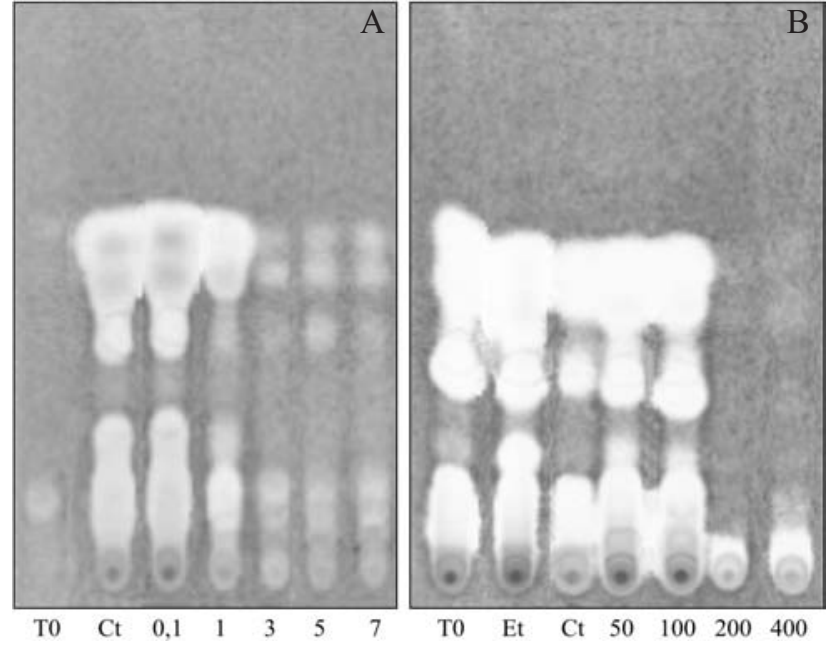

Figura 5. Bioautografia de extratos de células de $R$. jasminoides cultivadas em suspensão por 9 dias, incubadas por $264 \mathrm{~h}$ com nitroprussiato de sódio (A) e 96 horas com ácido salicílico (B), em diversas concentrações $(\mu \mathrm{M})$ ou com água destilada autoclavada $(\mathrm{Ct})$. $(\mathrm{T} 0=$ extratos de células antes da eliciação ou $\mathrm{Et}=$ de células incubadas com etanol a $20 \%$ ). As cromatoplacas foram desenvolvidas em clorofórmio: metanol (99:1 v/v) e reveladas com suspensão de esporos do fungo Cladosporium sphaerospermum. Foram utilizados $50 \mu \mathrm{L}$ dos extratos celulares.

Figure 5. Bioautography of cell suspension extracts of $R$. jasminoides with 9 days of culture, treated during $264 \mathrm{~h}$ with sodium nitroprusside (A) and 96 hours with salicylic acid in different concentrations $(\mu \mathrm{M})$ or autoclaved distilled water $(\mathrm{Ct}) .(\mathrm{T} 0=$ cell extracts before elicitation and $\mathrm{Et}=$ extract of cells treated with $20 \%$ ethanol). The plates were developed in chloroform: methanol $(99: 1 \mathrm{v} / \mathrm{v})$ and revealed with spore suspension of Cladosporium sphaerospermum. Fifty $\mu \mathrm{L}$ of cellular extracts were applied in the plates.

Os resultados obtidos sugerem que o NO não tem função de eliciador de síntese de compostos secundários em $R$. jasminoides, diferentemente do observado por Xu \& Dong (2005) na indução da síntese de alcalóides em suspensões celulares de Catharanthus roseus (L.) G. Don. Esses comportamentos opostos podem estar relacionados às diferentes doses testadas. $\mathrm{O} \mathrm{NO}$ atua sinergisticamente com espécies reativas de oxigênio na indução de respostas de defesa em plantas e alterações no equilíbrio entre essas moléculas poderiam explicar, em parte, tanto o efeito tóxico quanto de proteção dessa molécula em suspensões celulares (Delledonne et al. 2001, 2002).

Pela figura 5B, nota-se efeito inibitório do AS na produção de substâncias antifúngicas nas concentrações
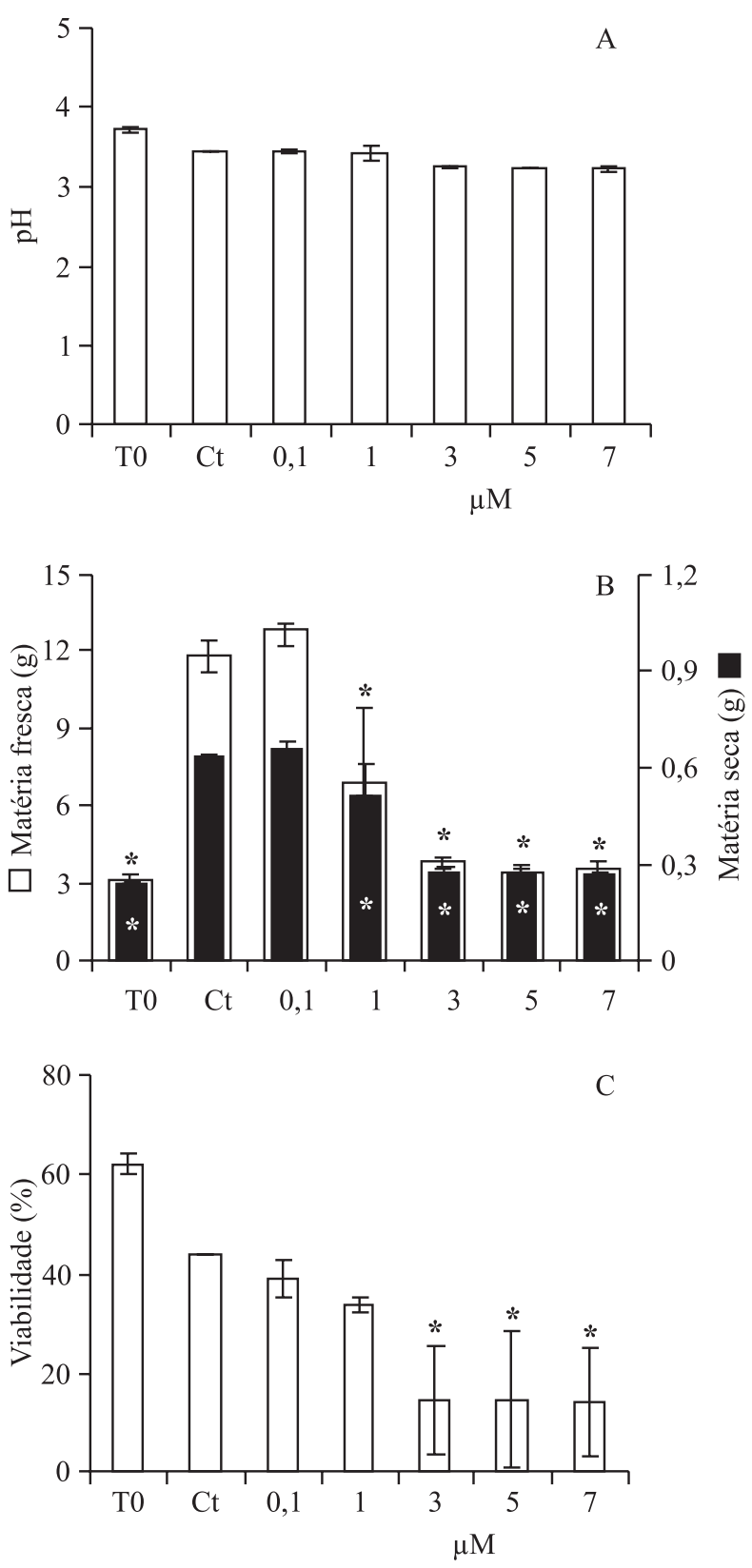

Figura 6. Valores de $\mathrm{pH}$ dos meios de cultivo (A), matérias fresca e seca (B) e viabilidade (C) de células de $R$. jasminoides cultivadas em suspensão, com 9 dias de idade, incubadas por 264 horas com nitroprussiato de sódio $(\mu \mathrm{M})$ ou com água destilada autoclavada $(\mathrm{Ct})$. ( $\mathrm{T} 0=$ extratos de células antes da eliciação). As barras representam o desvio padrão das médias (triplicatas). Os asteriscos $(*)$ indicam diferenças significativas em relação ao controle $(\mathrm{Ct})$ pelo teste de Tukey $(P<0,05)$.

Figure 6. Culture medium $\mathrm{pH}(\mathrm{A})$, fresh and dry masses (B), and viability of 9-day-old cell suspension of $R$. jasminoides, treated during 264 hours with sodium nitroprusside $(\mu \mathrm{M})$ or autoclaved distilled water $(\mathrm{Ct})$. $(\mathrm{T} 0=$ cell extracts before elicitation). Bars represent standard deviation of the mean of triplicates. The asterisks $(*)$ indicate significant differences in relation to control $(\mathrm{Ct})$ by Tukey $(P<0.05)$. 
de 200 e $400 \mu \mathrm{M}$, que mostraram efeito muito tóxico às células. Foi observada alcalinização do meio de cultura (figura 7A), acompanhada por redução das matérias fresca e seca (figura 7B) e 100\% de morte celular (figura 7C).

De acordo com estes resultados, o AS não age como molécula eliciadora de síntese de compostos antifúngicos em células de $R$. jasminoides nas condições ensaiadas (figura 5B). Em plântulas de Psychotria brachyceras Müll. Arg. (Rubiaceae), a aplicação exógena dessa molécula também não afetou a síntese de braquicerina (Gregianini et al. 2004). Entretanto, em cultivo de raízes de Brugmansia candida Pers. (Pitta-Alvarez et al. 2000) e suspensões celulares de Taxus chinensis var. mairei (Wang et al. 2007) foi observado aumento na síntese de alcalóides e de taxol, respectivamente, pelo uso de AS, porém, em concentrações diferentes das utilizadas neste trabalho. Essas diferenças podem ser explicadas pelo fato dessa molécula ser um indutor da resistência sistêmica adquirida na interação planta-patógeno, mas não um sinalizador universal da síntese de metabólitos no processo de defesa vegetal (Zhao et al. 2005). No entanto, o AS pode induzir a expressão de genes relacionados à biossíntese de algumas classes de compostos secundários em plantas (Taguchi et al. 2001). Além disso, conforme citado por Orbán et al. (2008), embora AS apresente ação regulatória no controle da síntese de antraquinonas em $R$. tinctorum seu efeito diverge daquele observado para eliciadores fúngicos.

Os dados obtidos neste trabalho mostram que substâncias antifúngicas estão presentes constitutivamente em tecidos foliares e suspensões celulares de $R$. jasminoides, embora maior quantidade e diversidade tenham sido encontradas no cultivo celular, como já relatado para outras espécies de Rubiaceae (Abdullah et al. 1998). As células de $R$. jasminoides são capazes de reconhecer eliciadores de origem fúngica, como o extrato de leveduras e eliciadores endógenos como os OGAs derivados de folhas da própria espécie, cujos efeitos estão relacionados à antecipação e ao incremento da síntese desses metabólitos de defesa. A ação distinta dos OGAs de origens diversas indica diferenças no reconhecimento e especificidade de moléculas eliciadoras similares. Esse comportamento diferencial dos OGAs abre perspectivas para o uso de moléculas endógenas na indução de mecanismos de defesa na própria planta, com potencial aplicação na agricultura.

Embora a caracterização química não tenha sido objeto deste trabalho, é provável que muitas das substâncias antifúngicas produzidas constitutivamente ou após indução com eliciadores em suspensões celulares
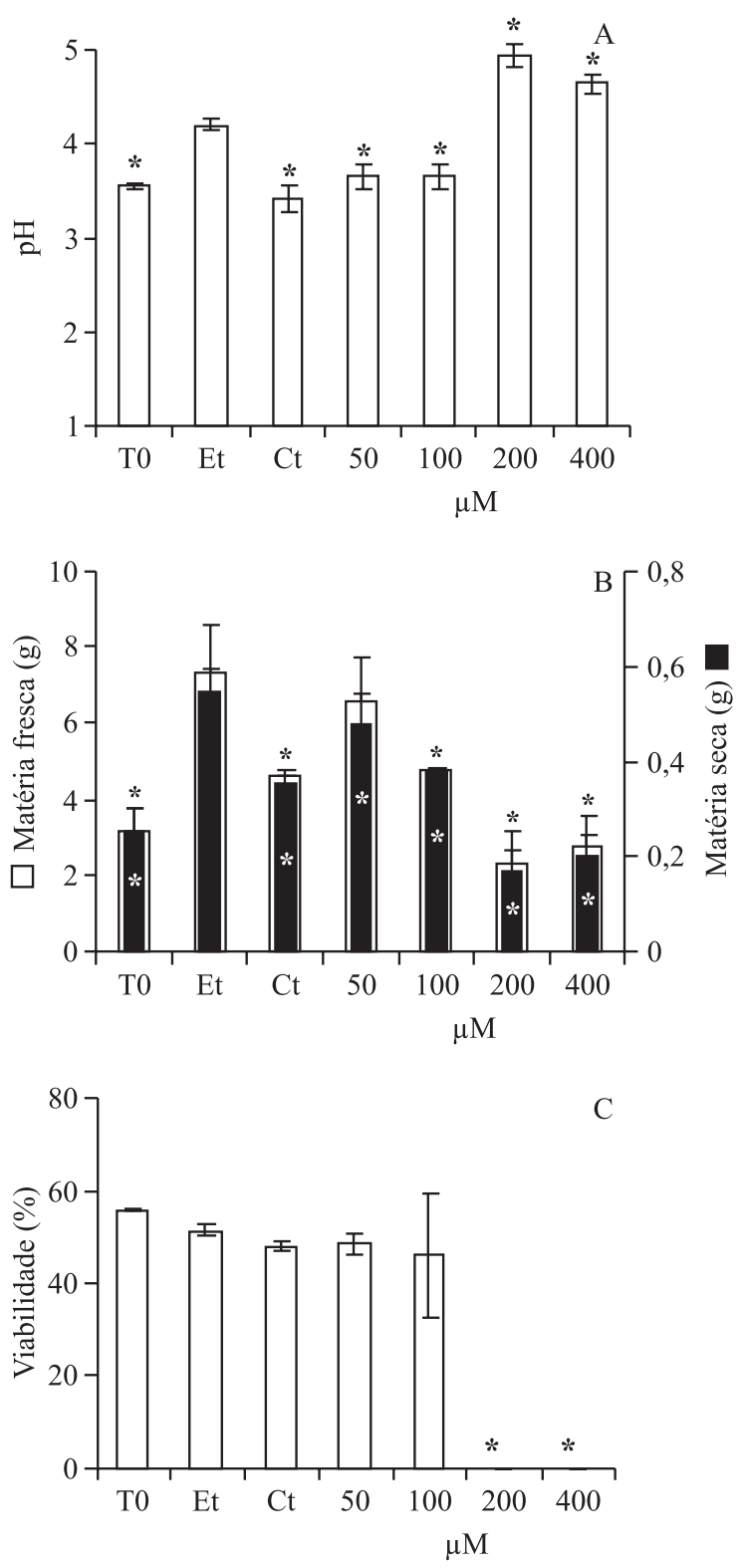

Figura 7. Valores de $\mathrm{pH}$ dos meios de cultivo (A), matérias fresca e seca (B) e viabilidade (C) de células de $R$. jasminoides cultivadas em suspensão, com 9 dias de idade, incubadas por 96 horas com ácido salicílico $(\mu \mathrm{M})$ ou com água destilada autoclavada $(\mathrm{Ct})$. (T0 = extratos de células antes da eliciação e Et $=$ extratos de células tratadas com etanol a 20\%). As barras representam o desvio padrão das médias (triplicatas). Os asteriscos $\left(^{*}\right)$ indicam diferenças significativas em relação ao controle $(\mathrm{Ct})$ pelo teste de Tukey $(P<0,05)$.

Figure 7. Culture medium $\mathrm{pH}(\mathrm{A})$, fresh and dry masses (B), and viability of 9-day-old cell suspension of $R$. jasminoides, treated during 96 hours with salicylic acid $(\mu \mathrm{M})$ or autoclaved distilled water $(\mathrm{Ct}) .(\mathrm{T} 0=$ cell extracts before elicitation and $\mathrm{Et}=$ extract of cells treated with $20 \%$ ethanol). Bars represent standard deviation of the mean of triplicates. The asterisks $(*)$ indicate significant differences in relation to control $(\mathrm{Ct})$ by Tukey $(P<0.05)$. 
de $R$. jasminoides sejam antraquinonas e naftoquinonas, metabólitos que caracterizam quimicamente a família Rubiaceae, sendo bastante comuns na subfamília Rubioideae, na qual $R$. jasminoides está incluída (Young et al. 1996). Essa sugestão é reforçada pelo trabalho de Oliveira et al. (2007) que recentemente relataram a presença de uma antraquinona sintetizada constitutivamente e de uma naftoquinona induzida pelo tratamento com eliciador de $S$. cerevisiae em culturas celulares dessa espécie.

A ocorrência de grande número de metabólitos antifúngicos constitutivos, o aumento da produção dos mesmos por ação de eliciadores e a indução da síntese $d e$ novo de outras substâncias por esses eliciadores fazem com que suspensões celulares de $R$. jasminoides sejam um sistema adequado para o estudo da produção e das rotas de biossíntese de compostos de defesa em rubiáceas nativas.

Agradecimentos - Os autores agradecem à Capes pela bolsa de Doutorado concedida a M.C. Oliveira, a Fapesp pela bolsa de Doutorado à K. Simões e ao CNPq pela bolsa de Produtividade em Pesquisa a M.R. Braga. Este trabalho foi realizado com apoio financeiro da Fapesp (98/05124-8, 05/04139-7).

\section{Referências bibliográficas}

ABDULLAH, M.A., ALI, A.M., MARZIAH, M., LAJIS, N.H. \& ARIFF, A.B. 1998. Establishment of cell suspension cultures of Morinda elliptica for the production of anthraquinones. Plant Cell, Tissue and Organ Culture 54:173-182.

AKHTAR, M.S., ALI, M., MADHURIYA, M., MIR, S.R. \& SINGH, O. 2006. New anthraquinones from Rubia cordifolia roots. Indian Journal of Chemistry Section B - Organic Chemistry 45:1945-1950.

BANTHORPE, D.V. 1994. Secondary metabolism in plant tissue culture: scope and limitations. Natural Product Reports 11:303-328.

BARZ, W., BEIMEN, A., DRAE, B., JAQUES, U., OTTO, C., SUE, E. \& UPMEIER, B. 1990. Turnover and storage of secondary products in cell cultures. In Secondary products from plant tissue culture (B.V. Charlwood \& M.J.C. Rhodes, eds.). Clarendon, Oxford, p.9-102.

BELLINCAMPI, D., CARDARELLI, M., ZAGHI, D., SERINO, G., SALVI, G., GATZ, C., CERVONE, F., ALTAMURA, M.M., CONSTANTINO, P. \& DE LORENZO, G. 1996. Oligogalacturonides prevent rhizogenesis in rol $B$ transformed tobacco explants by inhibiting auxin-induced expression of the rol $B$ gene. Plant Cell 8:477-487.
BOLZANI, V.D.S., IZUMISAWA, C.M., YOUNG, M.C.M., TREVISAN, L.M.V., KINGSTON, D.G.I. \& GUNATILAKA, A.L. 1997. Iridoids from Tocoyena formosa. Phytochemistry 46:305-308.

BRAGA, M.R., YOUNG, M.C.M., PONTE, J.V.A., DIETRICH, S.M.C., EMERENCIANO, V.D. \& GOTTLIEB, O.R. 1986. Phytoalexin induction in plants of tropical environment. Biochemical Systematics and Ecology 14:507-514.

BRAGA, M.R., YOUNG, M.C.M., DIETRICH, S.M.C. \& GOTTLIEB, O.R. 1991. Phytoalexin induction in Rubiaceae. Journal of Chemical Ecology 17:1079-1090.

BRAGA, M.R., PESSONI, R.A. \& DIETRICH, S.M.C. 1998. Cell wall polysaccharide composition of leaves of tropical Rubiaceae differing in phytoalexin response. Revista Brasileira de Fisiologia Vegetal 10:71-78.

CHONG, T.M., ABDULLAH, M.A., LAI, O.M., NOR'AINI, F.M. \& LAJIS, N.H. 2005. Effective elicitation factors in Morinda elliptica cell suspension culture. Process Biochemistry 40:3397-3405.

COLLU, G., GARCIA, A.A., VAN DER HEIJDEN, R. \& VERPOORTE, R. 2002. Activity of the cytochrome P450 enzyme geranyol 10-hydroxylase and alkaloid production in plant cell cultures. Plant Science 162:165-172.

CORDEIRO NETO, F. \& DIETRICH, S.M.C. 1992. Phytoalexin induction by leaf-surface fungi of tropical Rubiaceae. Ciência e Cultura 44:342-344.

DELLEDONNE, M., ZEIER, J., MAROCCO, A. \& LAMB, C. 2001. Signal interactions between nitric oxide and reactive oxygen intermediates in the plant hypersensitive disease resistance response. Proceedings of the National Academy of Sciences of the United States of AmericaBiological Sciences 98:13454-13459.

DELLEDONNE, M., MURGIA, I., EDERLE, D., SBICEGO, P.F., BIONDANI, A., POLVERARI, A. \& LAMB, C. 2002. Reactive oxygen intermediates modulate nitric oxide signaling in the plant hypersensitive diseaseresistance response. Plant Physiology and Biochemistry 40:605-610.

DINDA, B., DEBNATH, S., ARIMA, S., SATO, N. \& HARIGAYA, Y. 2006. Iridoid glucosides from Wendlandia tinctoria roots. Chemical Pharmaceutical Bulletin 54:1030-1033.

DUBOIS, M., GILLES, K.A., HAMILTON, J.K., REBERS, P.A. \& SMITH, F. 1956. Colorimetric method for determination of sugars and related substances. Analytical Chemistry 28:350-356.

FILISETTI-COZZI, T.M.C.C. \& CARPITA, N.C. 1991. Measurement of uronic acids without interference from neutral sugars. Analytical Biochemistry 197:157-162.

FRY, S.C. 1988. The growing plant cell wall: chemical and metabolic analysis. Longman, New York.

GOTTLIEB, O.R. 1982. Micromolecular evolution, systematics and ecology, an essay into a novel botanical discipline. Springer-Verlag, Heidelberg. 
GREGIANINI, T.S., PORTO, D.D., NASCIMENTO, N.C., FETT, J.P., HENRIQUES, A.T. \& FETT-NETO, A.G. 2004. Environmental and ontogenetic control of accumulation of brachycerine, a bioactive indole alkaloid from Psychotria brachyceras. Journal of Chemical Ecology 30:2023-2036.

HAHN, M.G. 1996. Microbial elicitors and their receptors in plants. Annual Review of Phytopathology 34:387-412.

HAN, Y.-S., VAN DER HEIJDEN, R. \& VERPOORTE, R. 2001. Biosynthesis of anthraquinones in cell cultures of the Rubiaceae. Plant Cell Tissue and Organ Culture 67:201-220.

HAN, Y.-S., VAN DER HEIJDEN, R., LEFEBER, A.W.M., ERKELENS, C. \& VERPOORTE, R. 2002. Biosynthesis of anthraquinones in cell cultures of Cinchona "Robusta" proceeds via the methylerythritol 4-phosphate pathway. Phytochemistry 59:45-55.

HOMANS, A.L. \& FUCHS, A. 1970. Direct bioautography on thin-layer chromatograms as a method for detecting fungitoxic substances. Journal of Chromatography 51:327-329.

HU, F.-X. \& ZHONG, J.-J. 2008. Jasmonic acid mediates gene transcription of ginsenoside biosynthesis in cell cultures of Panax notoginseng treated with chemically synthesized 2-hidroxyethyl jasmonate. Process Biochemistry 43:113118.

KOMARAIAH, P., KISHOR, P.B.K., CARLSSON, M., MAGNUSSON, K.-E. \& MANDENIUS, C.-F. 2005. Enhancement of anthraquinone accumulation in Morinda citrifolia suspension cultures. Plant Science 168:1337-1334.

MARQUES, M.R., BUCKERIDGE, M.S., BRAGA, M.R. \& DIETRICH, S.M.C. 2006. Characterization of an extracellular endopolygalacturonase from the saprobe Mucor ramosissimus Samutsevitsch and its action as trigger of defensive response in tropical plants. Mycopathologia 162:337-346.

MAURO, M.L., DE LORENZO, G., COSTANTINO, P. \& BELLINCAMPI, D. 2002. Oligogalacturonides inhibit the induction of late but not of early auxin-responsive genes in tobacco. Planta 215:494-501.

MCCALL, A.C. \& KARBAN, R. 2006. Induced defense in Nicotiana attenuata (Solanaceae) fruit and flowers. Oecologia 146:566-57.

MURASHIGE, T. \& SKOOG, F. 1962. A revised medium for rapid growth and bioassays with tobacco tissue cultures. Physiologia Plantarum 15:473-497.

OLIVEIRA, M.C., NEGRI, G., SALATINO, A. \& BRAGA, M.R. 2007.Detection of anthraquinones and identification of 1,4-naphtohydroquinone in cell suspension cultures of Rudgea jasminoides (Cham.) Müll. Arg. (Rubiaceae). Revista Brasileira de Botânica 30:167-172.

ORBÁN, N., BOLDIZSÁR, I., SZÜCS, Z. \& DÁNOS, B. 2008. Influence of different elicitors on the synthesis of anthraquinone derivatives in Rubia tinctorum L. cell suspension cultures. Dyes and Pigments 77:249-257.
PITTA-ALVAREZ, S.I., SPOLLANSKY, T.C. \& GIULIETTI, A.M. 2000. The influence of different biotic and abiotic elicitors on the production and profile of tropane alkaloids in hairy root cultures of Brugmansia candida. Enzyme and Microbial Technology 26:252-258.

RIDLEY, B.L., O’NEILL, M.A. \& MOHNEN, D. 2001. Pectins: structure, biosynthesis, and oligogalacturoniderelated signaling. Phytochemistry 57:929-967.

SANG, S.M. \& HO, C.T. 2006. Chemical components of noni (Morinda citrifolia). ACS Symposium Series 925:185194.

SAVIANI, E.E., ORSI, C.H., OLIVEIRA, J.F.P., PINTOMAGLIO, C.A.F. \& SALGADO, I. 2002. Participation of the mitochondrial permeability transition pore in nitric oxide-induced plant cell death. FEBS Letters 510:136-140.

SCHULTE, U., EL-SHAGI, H. \& ZENK, M.H. 1984. Optimization of 19 Rubiaceae species in cell culture for the production of anthraquinones. Plant Cell Reports 3:51-54.

SEYDEL, P. \& DÖRNENBURG, H. 2006. Establishment of in vitro plants, cell and tissue cultures from Oldenlandia affinis for the production of cyclic peptides. Plant Cell Tissue and Organ Culture 85:247-255.

STELlA, A. \& BRAGA, M.R. 2002. Callus and cell suspension cultures of Rudgea jasminoides, a tropical woody Rubiaceae. Plant Cell Tissue and Organ Culture 68:271-276.

TAGUCHI, G., YAZAWA, T., HAYASHIDA, N. \& OKAZAKI, M. 2001. Molecular cloning and heterologous expression of novel glucosyltransferases from tobacco cultured cells that have broad substrate specificity and are induced by salicylic acid and auxin. European Journal of Biochemistry 268:4086-4094.

TURNER, J.G. \& NOVACKY, A. 1974. The quantitative relationship between plant and bacterial cells involved in the hypersensitive reaction. Phytopathology 64:885-889.

VASCONSUELO, A. \& BOLAND, R. 2007. Molecular aspects of the early stages of elicitation of secondary metabolites in plants. Plant Science 172:861-875.

VITALI,A., PACINI, L., BORDI, E., DE MORI, P., PUCILLO, L., MARAS, B., BOTTA, B., BRANCACCIO, A. \& GIARDINA, B. 2006. Purification and characterization of an antifungal thaumatin-like protein from Cassia didymobotrya cell culture. Plant Physiology and Biochemistry 44:604-610.

WANG, Y.-D., WU, J.-C. \& YUAN, Y.-J. 2007. Salicylic acidinduced taxol production and isopentenyl pyrophosphate biosynthesis in suspension cultures of Taxus chinensis var. mairei. Cell Biology International 31:1179-1183.

WARZECHA, H., FRANK, A., PEER, M., GILLAM, E.M.J., GUENGERICH, F.P. \& UNGER, M. 2007. Formation of the indigo precursor indican in genetically engineered tobacco plants and cell cultures. Plant Biotechnology Journal 5:185-191. 
XU, M. \& DONG, J. 2005. Nitric oxide stimulates indole alkaloid production in Catharanthus roseus cell suspension cultures through a protein kinase-dependent signal pathway. Enzyme and Microbial Technology 37:49-53.

YAMAZAKI, Y., SUDO, H., YAMAZAKI, M., AIMI, N. \& SAITO, K. 2003. Camptothecin biosynthetic genes in hairy roots of Ophiorrhiza pumila: cloning, characterization and differential expression in tissues and by stress compounds. Plant and Cell Physiology 44:395-403.
YOUNG, M.C.M., BRAGA, M.R., DIETRICH, S.M.C., BOLZANI, V.S., TREVISAN, L.M.V. \& GOTTLIEB, O.R. 1996. Chemosystematic markers of Rubiaceae. Opera Botanica Belgica 7:205-212.

YOUNG, M.C.M., ARAÚJO, A.R., SILVA, C.A., LOPES, M.N., TREVISAN, L.M.V. \& BOLZANI, V.S. 1998. Triterpenes and saponins from Rudgea viburnoides. Journal of Natural Products 61:936-938.

ZHAO,J.,DAVIS,L.C.\&VERPOORTE,R.2005.Elicitorsignal transduction leading to production of plant secondary metabolites. Biotechnology Advances 23:283-333. 